\title{
Effect of host extract on growth and sporulation of Cercospora lactucae-sativae
}

\author{
Augustus Thomas $^{1} \cdot$ Duraisamy Saravanakumar $^{1}$
}

Received: 22 November 2018 / Accepted: 4 July 2019 / Published online: 9 July 2019

(C) Australasian Plant Pathology Society Inc. 2019

\begin{abstract}
Cercospora lactucae-sativae is a slow growing hemibiotrophic fungus that proves difficult to isolate and sporulate on many growth media. The study focussed on the use of a simple isolation procedure for $C$. lactucae-sativae and examined the effect of host extract on growth and sporulation of C. lactucae-sativae on PDA and Water Agar. The mean colony diameter was significantly greater than that of the control treatment for WA + LE at 1\%,2\% and 4\% only, and for all of the LE concentrations on PDA. The mean conidial concentration was significantly different from the control treatment for all concentrations on WA at and above $2 \%$ LE, while on PDA there were no significant differences between any of the treatment including the control. PCR has confirmed that the leaf spot disease affecting lettuce cultivation in Trinidad is caused by C. lactucae-sativae.
\end{abstract}

Keywords Cercospora lactucae-sativae $\cdot$ Hemibiotrophic fungus $\cdot$ Lettuce extract $\cdot$ Pure culture

Lettuce is one of the most prevalent leafy vegetables produced under open and protected conditions including hydroponics in Trinidad with an annual production of 2810 tonnes (CSO 2015). The cultivation of lettuce is seriously affected by a leaf spot disease incited by Cercospora lactucae-sativae throughout the cropping period. It is prevalent during the rainy as well as dry seasons causing yield losses up to $80 \%$. The common practice of overhead irrigation encourages the spread of conidia. The infection begins on the lower older leaves and progresses to the younger ones. Lesions are lightdark brown, surrounded by a yellow halo and further characterised by a light ash to white coloured dot about size of the pinhole ( $1 \mathrm{~mm}$ wide) in the center of the lesion (Fig. 1). The isolation and detection of Cercospora species is difficult due to its slow growth and poor sporulating nature on culture media (Goode and Brown 1970). A single spore technique (Choi et al. 1999) has been reported as more suitable and successful for isolation of slow growing fungi. Further, an amendment of host extract in the media was reported

Duraisamy Saravanakumar

duraisamy.saravanakumar@sta.uwi.edu

1 Department of Food Production, Faculty of Food and Agriculture, The University of the West Indies, St. Augustine, Trinidad and Tobago as one of the methods to stimulate sporulation in hemibiotrophic and biotrophic fungi (Jacome et al. 1991; Huerta-Espino et al. 2006). However, the technique has not been standardised for isolation of Cercospora from lettuce. Therefore, the standardisation of isolation and sporulation techniques for Cercospora of lettuce have become necessary to our research team for the characterisation of the pathogen, screening of resistance and development of management practices.

Lettuce leaves with the characteristic symptom of cercospora leaf spot were collected from the farmer's

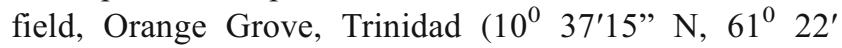
14 " W). Lesions with surrounding green tissues 10 $20 \mathrm{~mm}$, were excised from the leaves and surface sterilised in $5 \% \mathrm{NaOCl}$ for $15 \mathrm{~s}$, then rinsed thoroughly in sterile water. The surface of the leaf sections were dried and transferred to sterile Petri dishes $(90 \mathrm{~mm})$ containing filter paper saturated with sterile water. The plates were incubated at $28^{\circ} \mathrm{C}$ in complete darkness. After four days of incubation, leaf tissue was transferred from the filter paper to $5 \mathrm{~mL}$ sterile water and agitated to dislodge conidia from the sample. A drop of the conidial suspension was examined under a microscope to confirm the sole presence of Cercospora conidia. One hundred (100) $\mu \mathrm{L}$ aliquots of the suspension were transferred onto potato dextrose agar (PDA) plates $(90 \mathrm{~mm})$ amended with the antibiotic chlortetracycline at $200 \mathrm{mg} \mathrm{L}^{-1}$ and spread evenly with a sterile L- 


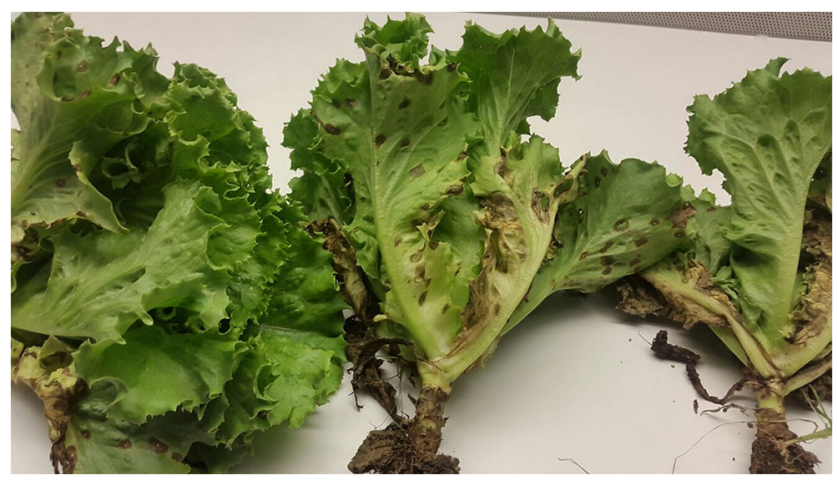

Fig. 1 Lettuce plants collected from the field expressing symptoms of cercospora leaf spot

shaped glass rod. After $24 \mathrm{~h}$ of incubation in complete darkness at $28^{\circ} \mathrm{C}$, the plates were examined for single germinating conidia with the aid of a light microscope (Olympus CX23 at 10X). Then, a small agar block with a single germinated conidium was transferred to a Petri plate containing PDA. The plates were incubated at $28^{\circ} \mathrm{C}$ under a $12 \mathrm{~h}$ light $/ 12 \mathrm{~h}$ dark regime for 9 days.

On PDA, colonies were dark brown-greenish black, uneven and raised with folds $17-21 \mathrm{~mm}$ in diameter after 9 days of incubation, with hyphae being septate and pigmented. The conidia, mounted with sterile water on a microscope slide and examined at 40X magnification, were hyaline, cylindrical, straight-slightly curved, with blunt or round tips, 2-15 septate and $12-236 \times 4$ $10 \mu \mathrm{m}$ (Fig. 2). This morphology is slightly different to that $(10-20$ septate and $20-220 \times 3.5-5 \mu \mathrm{m})$ provided for conidia of C. lactucae-sativae by McKenzie (2013).

Confirmation of the pathogen was performed by extraction of DNA from mycelium of a 7-day-old culture using the Promega DNA extraction kit. The quantification of DNA was done using photometer and gel electrophoresis in $0.8 \%$ agarose gel containing $0.05 \%$

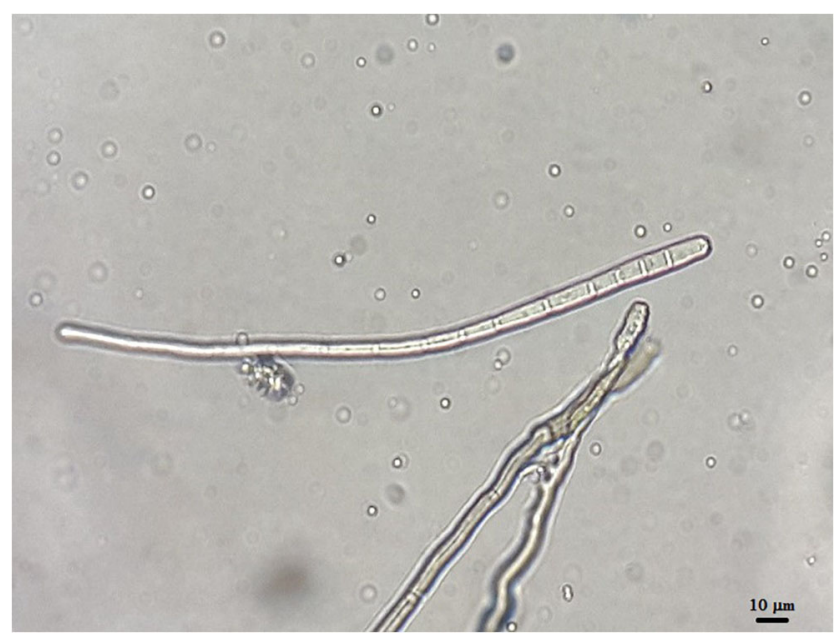

Fig. 2 Conidia from lettuce plants inoculated with C. lactucae-sativae ethidium bromide. The Internal Transcribed Spacers (ITS) ITS1 (5'TCCGTAGGTGAACCTGCGG3') and ITS4 (5'TCCTCCGCTTATTGATATGC-3') were used as forward and reverse primers respectively in PCR amplification. PCR was carried out in $20 \mu \mathrm{L}$ reaction mixtures containing $10 \mathrm{X}$ buffer (with $2.5 \mathrm{mM} \mathrm{MgCl}_{2}$ ), $2 \mu \mathrm{L} ; 2 \mu \mathrm{mM}$ dNTP mixture, $2 \mu \mathrm{L} ; 2 \mu \mathrm{M}$ primer, $2 \mu \mathrm{L}$; Taq DNA polymerase, $3 \mathrm{U}$; and $50 \mathrm{ng}$ of template DNA. In order to ensure the reproducibility of the reaction, appropriate negative controls (without DNA template) were also run. PCR conditions included an initial denaturation at $95^{\circ} \mathrm{C}$ for $2 \mathrm{~min}, 35$ cycles of $95^{\circ} \mathrm{C}$ for $30 \mathrm{~S}, 55^{\circ} \mathrm{C}$ for $30 \mathrm{~S}$ and $72^{\circ} \mathrm{C}$ for $1 \mathrm{~min}$ and final extension for $10 \mathrm{~min}$ at $72^{\circ} \mathrm{C}$. PCR product was resolved on $2 \%$ agarose at $50 \mathrm{~V}$ stained with ethidium bromide $\left(0.5 \mu \mathrm{g} \mathrm{mL}^{-1}\right)$ to measure the amplified DNA. ITS1 and ITS4 primers amplified a DNA fragment of $\cong 550 \mathrm{bp}$. Amplified PCR product was purified and sequenced at Macrogen, South Korea. It showed $99 \%$ homology to C. lactucae-sativae strain CPC24838 in NCBI database reported from Northern Thailand (Accession No. KT193676). DNA sequence has revealed that the pathogen affecting lettuce in Trinidad was $C$. lactucae-sativae. The sequence data of the isolate MAL1 was submitted to NCBI with Accession No. MH216663. One representative isolate was deposited in the International Collection of Microorganisms from Plants, Auckland, New Zealand with the accession number ICMP 22703.

Lettuce seedlings (cv. Trinity) were raised in 128-cell black plastic seedling trays containing soil-less media of peat moss and perlite (The Green Formula, Canada) and transplanted after 21 days into potting mix (promix:soil at 1:1) in Styrofoam cups $(130 \times 90 \times 60 \mathrm{~mm})$ in semicontrolled greenhouse conditions. A conidial suspension was prepared from a 10-day-old culture of C. lactucaesativae. The conidia were harvested by adding $5 \mathrm{~mL}$ of sterile water onto mycelium grown on Petri plates. The mycelium was gently scraped using a L-shaped glass rod and then filtered through cheese cloth. The filtrates were assessed for the presence of conidia and concentration was adjusted to $10^{3}$ conidia $\mathrm{mL}^{-1}$ using a haemocytometer (Hausser $\geq$ Scientific, Horsham, UK). Ten seedlings were inoculated with a conidial suspension using a hand-held sprayer to the point of leaf saturation but avoiding runoff while another 10 plants were sprayed with sterile water. The humidity inside the greenhouse was maintained by keeping the floor moist and misting twice a day. After 7 days, the seedlings inoculated with conidia displayed light-dark brown lesions, 3-5 $\mathrm{mm}$ in diameter with a yellow halo, typical symptoms of cercospora leaf spot. Leaf samples from inoculated and uninoculated plants were collected and 
Table 1 Effect of host extract on growth and sporulation of C. lactucae-sativae in two different media

\begin{tabular}{|c|c|c|c|c|}
\hline \multirow[t]{2}{*}{ Treatment } & \multicolumn{2}{|c|}{ Mean colony diameter (mm) } & \multicolumn{2}{|c|}{ Mean conidium concentration* (conidia/mL) } \\
\hline & WA & PDA & WA & PDA \\
\hline $0 \% \mathrm{LE}$ & $15.1 \mathrm{ab}$ & $16.1 \mathrm{abc}$ & $\begin{array}{l}7.97 \times 10^{3} \\
(3.82) \mathrm{a}\end{array}$ & $\begin{array}{l}1.50 \times 10^{4} \\
(3.84) \mathrm{ab}\end{array}$ \\
\hline $1 \% \mathrm{LE}$ & $21.3 \mathrm{f}$ & $20.6 \mathrm{ef}$ & $\begin{array}{l}4.71 \times 10^{4} \\
(3.86) \mathrm{ab}\end{array}$ & $\begin{array}{l}2.63 \times 10^{4} \\
(4.28) \mathrm{abc}\end{array}$ \\
\hline $2 \% \mathrm{LE}$ & $20.6 \mathrm{ef}$ & $20.8 \mathrm{ef}$ & $\begin{array}{l}6.89 \times 10^{4} \\
(4.67) \text { cde }\end{array}$ & $\begin{array}{l}3.23 \times 10^{4} \\
(4.38) \mathrm{abcd}\end{array}$ \\
\hline $4 \% \mathrm{LE}$ & $18.1 \mathrm{~cd}$ & $20.1 \mathrm{def}$ & $\begin{array}{l}1.51 \times 10^{5} \\
(4.95) \mathrm{cde}\end{array}$ & $\begin{array}{l}3.90 \times 10^{4} \\
(4.42) \mathrm{abcd}\end{array}$ \\
\hline $8 \% \mathrm{LE}$ & $14.1 \mathrm{a}$ & $18.8 \mathrm{de}$ & $\begin{array}{l}2.42 \times 10^{5} \\
(5.16) \mathrm{de}\end{array}$ & $\begin{array}{l}2.48 \times 10^{4} \\
(4.25) \mathrm{abc}\end{array}$ \\
\hline $16 \% \mathrm{LE}$ & $16.4 \mathrm{bc}$ & $19.6 \mathrm{def}$ & $\begin{array}{l}2.39 \times 10^{5} \\
(5.07) \mathrm{de}\end{array}$ & $\begin{array}{l}4.94 \times 10^{4} \\
(4.51) \mathrm{abcd}\end{array}$ \\
\hline $20 \% \mathrm{LE}$ & $15.3 \mathrm{ab}$ & $19.9 \mathrm{def}$ & $\begin{array}{l}2.76 \times 10^{5} \\
(5.34) \mathrm{e}\end{array}$ & $\begin{array}{l}5.55 \times 10^{4} \\
(4.67) \mathrm{abcd}\end{array}$ \\
\hline
\end{tabular}

LE lettuce extract; WA Water Agar; PDA Potato Dextrose Agar

*Values in parenthesis are log transformed

Above values are mean of four replications

For both mean colony diameter and mean conidium concentration, mean values followed by the same letter are not significantly different from each other $(P=0.05)$

used for isolation of the pathogen. The technique was the same as described in the initial isolation of the pathogen from infected leaf samples.

C. lactucae-sativae was successfully isolated from the lesions on inoculated plants, thereby fulfilling Koch's postulates. No lesions developed on the uninoculated control plants.

Since the sporulation of C. Lactucae-sativae proved to be difficult on plain PDA, the influence of host extract on colony diameter and sporulation of $C$. lactucae-sativae was explored. Healthy lettuce leaves weighed to 10, 20, 40, 80, 160, $200 \mathrm{~g}$ were homogenised in $400 \mathrm{~mL}$ of distilled water separately and transferred to individual $1000 \mathrm{~mL}$ flask to obtain lettuce extract (LE) concentrations of $1 \%, 2 \%, 4 \%, 8 \%, 16 \%$ and $20 \%$, respectively. PDA was added at $39 \mathrm{~g}$ per $\mathrm{L}$ to flasks containing different concentrations of LE. Each flask was made up to $1 \mathrm{~L}$ and then inverted several times to homogenise the mixture. Similarly, Water Agar (WA) was prepared (15 g per L) in separate bottles with LE of $1 \%, 2 \%, 4 \%, 8 \%, 16 \%$ and $20 \%$. The media amended with LE were autoclaved at $121^{\circ} \mathrm{C}$ and $103.4 \mathrm{kPa}$ for $20 \mathrm{~min}$ and used for sporulation studies. WA and PDA prepared without LE has served as control treatments. A block of agar $(4 \times 4 \mathrm{~mm})$ colonised with 7-day-old C. lactucae-sativae was transferred to the centre of each Petri dish containing PDA and WA amended with and without different concentrations of LE. A completely randomised block design was adopted, with four replicates of each treatment. After 9 days of incubation at $25^{\circ} \mathrm{C}$, the diameter of each colony was measured. A conidial suspension was prepared using $5 \mathrm{~mL}$ of sterile water as previously described. The conidium concentration was assessed using a haemocytometer.

Data on the effect of LE concentrations on WA and PDA were combined separately for both colony diameter and conidium concentration before analyses of variance (ANOVA) using the Statistical Package for Social Sciences (SSPS v.2). The mean conidium concentration was transformed into log values for analysis.

Amendment of WA with 1\%, 2\% and 4\% LE concentrations significantly increased the mean colony diameter compared to the control treatment. The mean colony diameter for all concentrations of $\geq 1 \%$ LE + PDA were significantly greater than the control treatment. An increase in LE concentration significantly increased conidial concentration on WA at $\geq 2 \%$ LE. However, there were no significant differences in conidial concentration among the different concentrations of LE + PDA and the control treatment (Table 1).

The current study has found that the largest colony diameter was at $\mathrm{WA}+1 \% \mathrm{LE}$ and the greatest conidium concentration was at WA $+20 \%$ LE. Nevertheless, the best combination to obtain high colony diameter and conidium concentration is $\mathrm{WA}+4 \%$ LE since it offered a compromise, with both the growth and sporulation being significantly better than the control treatment.

The isolation of C. lactucae-sativae using preincubation of infected lettuce leaves on moist filter paper has resulted in successful isolation of the lettuce leaf spot pathogen. The current isolation technique has shown to be simple and effective in the acquisition of pure cultures of hemibiotrophic Cercospora from lettuce leaves. This technique is proposed as one of potential methods for isolation of the slow growing fungus. The methodologies regarding the isolation and in vitro growth and sporulation described in this paper will form the basis of future studies on the biology and management of $C$. lactucae-sativae on lettuce in Trinidad. 
Acknowledgements The research work was carried out as part of the UWI-TT RDI Fund on "Promoting agriculturally important microorganisms (AIMS) to address the challenges in food safety and food security in the Caribbean".

\section{References}

CSO, 2015. Central Statistical Office, Government of Trinidad and Tobago. Accessed: http://cso.gov.tt/data/?productID=126Estimated-Quantity-of-Food-Crops-Harvested-from-TraditionalCultivation-(Trinidad)

Choi Y, Hyde KD, Ho WH (1999) Single spore isolation of fungi. Fungal Divers 3:29-38
Goode MJ, Brown GR (1970) Detection and characterization of Cercospora citrullina isolates that sporulate readily in culture. Phytopathol 30:1502-1503

Huerta-Espino J, Constantinescu O, Velásquez C, Herrera-Foessel SA, Figueroa-López P (2006) First report of Ramularia cercosporelloides on Carthamus tinctorius in northwestern Mexico. Plant Dis 90:1552

Jacome LH, Schuh W, Steverson RE (1991) Effect of temperature and relative humidity on germination and germ tube development of Mycosphaerella fijiensis var. difformis. Phytopathol 12:1480-1485

McKenzie E (2013) Cercospora lactucae-sativae (Cercospora lactucaesativae). Accessed: http://www.padil.gov.au 